BBA 55953

\title{
SILICA GEL STIMULATES THE HYDROLYSIS OF LECITHIN BY PHOSPHOLIPASE A
}

\author{
J. GOERKE*, J. DE GIER AND P. P. M. BONSEN
}

Laboratory of Biochemisiry, State University of Utrecht, Utrecht (The Netherlands)

(Received July 26th, 1971)

\section{SUMMARY}

r. Silica gel stimulates the hydrolysis of aqueous lecithin suspensions by phospholipase $\mathrm{A}$. The activation is slightly greater than that caused by ether and takes place equally well in bulk suspensions of silica gel or on thin-layer chromatographic plates prepared with silica.

2. The hydrolyses of lecithin by phospholipase $\mathrm{C}$ and of triolein by lipase are not affected by silica under the reaction conditions employed.

3. In light of these findings, it is advisable to employ an independent means of stopping phospholipase A reactions prior to product separation in chromatographic systems.

\section{INTRODUCTION}

During phospholipase $A^{* *}$ degradation of lecithin to lysolecithin and fatty acid, the physical state of the substrate is very important. For example, sonication of lecithin suspensions greatly enhances their subsequent rate of enzymic hydrolysis. It is conceivable that routine manipulations in an experiment might produce a hidden stimulation of enzyme activity, or that the reaction might even continue when the experimentor thought it to have stopped. In this regard, phospholipase A action is said to persist in common solvent extraction media ${ }^{1,2}$, and other solvents such as ether $^{3}$ and methyl isobutyl ketone ${ }^{2,4}$ are known to stimulate the reaction.

Some authors have used direct application of reaction mixtures onto chromatographic media, apparently in an attempt to avoid this problem ${ }^{5}$. However, since the anionic dispersing agent deoxycholate is a potent activator of phospholipase $\mathrm{A}^{6}$, it is possible that chromatographic media themselves might play such a dispersingactivating role. The experiments recounted below show that silica gel is indeed a powerful activator of phospholipase $A$, and may provide an cxplanation for the intriguing observations of FRANCK et al. ${ }^{5}$ who claim to have found reacylation of

* Present address: Cardiovascular Research Institute and Department of Medicine, University of California, San Francisco, Calif. 94122 (U.S.A.).

** In this report phospholipase $\mathrm{A}$ is phospholipase $\mathrm{A}_{2}$. 
lysolecithin when EDTA was added to the reaction products of phospholipase A hydrolysis.

\section{MATERIALS}

The phospholipase A substrates were a purified soya bean lecithin and egg lecithin. Soya lecithin was the gift of Dr. H. Eikermann of Nattermann and Co., Köln, Germany, and was used without further purification. On thin-layer chromatography it contained trace amounts of materials with the mobilities of lysolecithin, fatty acid and neutral lipids. Egg lecithin was prepared from fresh eggs ${ }^{7}$, and both lecithins were kept at $-\mathrm{IO}^{\circ}$ in chloroform solution. Chromatographically pure triolein was supplied by Dr. G. H. de Haas. Other compounds were either of reagent grade or of the highest purity available. Chloroform and methanol were redistilled prior to use. Silica gel $\mathrm{G}$ containing $\mathrm{I}_{3} \% \mathrm{CaSO}_{4}$ and Silica gel $\mathrm{H}$ were obtained from $\mathrm{E}$. Merck and Co., Darmstadt, Germany, and used without further treatment. Three sources of lyophilized phospholipase A were used: Crotalus adamanteus venom from KochLight Co., England, pure porcine pancreatic enzyme as a gift from Dr. G. H. de Haas, and bee venom from Fluka and Co., Switzerland. Partially purified phospholipase $C$ from Bacillus cereus was kindly supplied by Dr. R. Zwaal, and purc pancreatic lipase was given to us by Dr. R. Verger.

\section{METHODS}

\section{Substrate and enzyme stocks}

For bulk and thin-layer chromatographic reactions, stock $75 \mathrm{mM}$ suspensions of soya and egg lecithin were prepared in buffer (o.I $\mathrm{M}$ Tris, Io $\mathrm{mM} \mathrm{CaCl}, \mathrm{pH} 7.5$ ) by gentle agitation using a glass bead in a round bottom flask after vacuum evaporation of the stock chloroform solution. For some experiments these suspensions were further sonicated to clarity (ro min) using polyethylene vials placed in a Branson Model SI 25 well-type sonicator operated at setting No. 4 . In trial experiments sonication in glass vials had required 60 to 90 min to reach comparable clarity. An unsonicated glycine suspension of soya lecithin ${ }^{5}$ was also employed. For lipase experiments triolein was suspended by sonication for $6 \mathrm{~min}$ in o.I M Tris at $\mathrm{pH} \mathrm{7.5.} \mathrm{Enzymes} \mathrm{were}$ dissolved in appropriate buffers at $\mathrm{I} \mathrm{mg} / \mathrm{ml}$ concentration.

Reactions direclly on thin-layer chromatographic plates

Approximately 5- $\mu$ l amounts of stock enzyme and lecithin substrate were applied to the same thin-layer chromatographic origin spots with concurrent drying by a warm air blower. The plates were placed in developing solvent directly after a 2-min drying period.

\section{Bulk reaction mixtures}

The standard reaction mixture of $2 \mathrm{ml}$ contained Ioo $\mu \mathrm{g}$ of the phospholipase A under study and $7.5 \mu$ moles soya or egg lecithin in o.I $\mathrm{M}$ Tris, Io $\mathrm{mM} \mathrm{CaCl}_{2}$ at $\mathrm{pH}$ 7.5. Samples were spotted directly onto small thin-layer chromatographic plates from ice cold mixtures and from 20 -min incubations at room temperature. Simultancous samples were also extracted by the techniques of Folch et al. ${ }^{8}$ and BLIGH AND DYER ${ }^{9}$ before spotting on thin-layer chromatographic plates.

Biochim. Biophys. Acta, 248 (197 I) 245-253 
In addition to sonicated triolein, silica gel suspensions of the unsonicated material were also studied. These were prepared by vacuum evaporation of chloroform solutions of triolein in the presence of Silica gel $\mathrm{H}$, with subsequent suspension in o.I $\mathrm{M}$ Tris at $\mathrm{pH} 7.5$ to a final $7.5 \mu \mathrm{M}$ lipid concentration. The resulting silica gel concentration was $0.1 \mathrm{~g} / \mathrm{ml}$ buffer.

For those phospholipase A experiments involving a subsequent phosphorus analysis, $4 \mathrm{ml}$ of buffer were mixed with ${ }_{5} 5 \mu$ moles of suspended soya lecithin, and a $\mathrm{I}-\mathrm{ml}$ zero-time sample was removed. Crotalus adamanteus venom, $200 \mu \mathrm{g}$, was then added and I $\mathrm{ml}$ samples removed for analysis at 2 and $20 \mathrm{~min}$. Each I-ml sample was shaken with an extraction medium consisting of o.I $\mathrm{ml} 25^{\circ} \mathrm{mM}$ EDTA and 3.5 $\mathrm{ml}$ chloroform-methanol $(\mathrm{I}: 2, \mathrm{v} / \mathrm{v})$. The extraction was completed in the manner of BLIGH AND DYER ${ }^{9}$, the chloroform phase being taken to dryness and redissolved in $0.2 \mathrm{ml}$ chloroform. Duplicate $20-\mu \mathrm{l}$ samples were analysed by thin-layer chromatography. When ether or silica gel was used, I.I-ml samples were taken. In the experiment involving Ioo $\mathrm{mM} \mathrm{CaCl}_{2}$, appropriate increases in EDTA and the extraction media were used.

\section{Chromatography}

Thin-layer chromatographic plates of $2.5 \mathrm{~cm} \times 7.5 \mathrm{~cm}$ and $20 \mathrm{~cm} \times 20 \mathrm{~cm}$ were prepared with Silica gels $G$ and $H$. Points of application were dried for up to 2 min with a warm air blower. The developing solvent in phospholipase $A$ experiments was chloroform-methanol-water $(65: 35: 5, \mathrm{v} / \mathrm{v} / \mathrm{v})$. Spots on the small plates were estimated by $\mathrm{H}_{2} \mathrm{SO}_{4}$ charring and on the large plates by quantitative phosphorus analysis $^{10}$ of lecithin and lysolecithin spots identificd with iodine vapor. Soya lecithin, egg lysolecithin, and linoleic acid served as standards. Phospholipase $C$ and lipase activity were followed on the above thin-layer chromatographic plates, using heptane-ether $\left(5^{\circ}: 5^{\circ}, \mathrm{v} / \mathrm{v}\right)$ as developing solvent with batch-produced soya diglyceride and linoleic acid as standards. Silicic acid impregnated paper was also used and was developed in diisobutyl ketone-acetic acid-water $(40: 25: 5, \mathrm{v} / \mathrm{v} / \mathrm{v})$ with spot identification by tricomplex staining ${ }^{11}$.

\section{pH-stat titrations}

In some experiments the production of fatty acid was monitored in a $\mathrm{pH}^{-s_{t a t}}{ }^{12}$ (Radiometer Model TTT-IC Autotitrator with titragraph SBR2C) by titrating with $0.04 \mathrm{M} \mathrm{NaOH}$ to $\mathrm{pH} 8$ at $25^{\circ}$. Phospholipase A, $200 \mu \mathrm{g}$, was added to $4 \mathrm{Inl}$ of solution (o.I M KCl, $5 \cdot \mathrm{IO}^{-4} \mathrm{M}$ Tris, $4 \cdot \mathrm{IO}^{-3} \mathrm{M} \mathrm{CaCl}_{2}$ ) containing I $5 \mu$ moles of sonicated or unsonicated lecithin. Suspensions were usually incubated with enzyme until the reaction was $20 \%$ complete (approximately $20 \mathrm{~min}$ ) at which time EDTA was added to a final concentration of Io mM. $0.25 \mathrm{ml}$ samples were taken just after initial mixing and at $20 \%$ of completion, and were then mixed separately with $0.25 \mathrm{ml} \mathrm{I} \mathrm{M} \mathrm{HCl}$ and with $5^{\circ} \mu 10.25 \mathrm{M}$ EDTA. These mixtures and direct aliquots of the reaction mixtures were applied and run on small Silica gel $\mathrm{H}$ plates. In several experiments deoxycholate was added and the stimulated reaction allowed to go to completion in order to determine titration efficiency. 
RESULTS

\section{Phospholipase $A$ activity on thin-layer chromatographic plates}

When enzyme and substrate were applied directly to thin-layer chromatographic plates, a substantial hydrolysis of both soya and egg lecithin was always observed, as judged by $\mathrm{H}_{2} \mathrm{SO}_{4}$ charring. The breakdown ranged between Io and $70 \%$, the higher values being associated with prolonged dampness of the origins. All three enzymes (bee, snake, and porcine pancreatic) were active, and both the regular soya lecithin suspensions and the glycine suspension were hydrolysed as was egg lecithin. The order of application of enzyme and substrate was immaterial, and even lecithin spotted directly from chloroform solution was hydrolysed if it was applied prior to the aqueous enzyme solution. EDTA $(5 \mu \mathrm{l}$ of $50 \mathrm{mM}$ ) in either substrate or enzyme was sufficient to inhibit the reaction completely on both Silica gel $G$ and $H$ by removing the calcium required for enzyme activity. To test whether these hydrolyses took place during plate development, the pancreatic phospholipase was applied a short distance above soya lecithin so that the substrate would be carried over the enzyme during development. No lysolecithin was observed in this instance, indicating that thin-layer chromatographic-induced hydrolysis occurred only prior to plate development. Substantial activity (approximately 30\% hydrolysis) was also observed when enzyme and substrate were applied to silica impregnated chromatographic
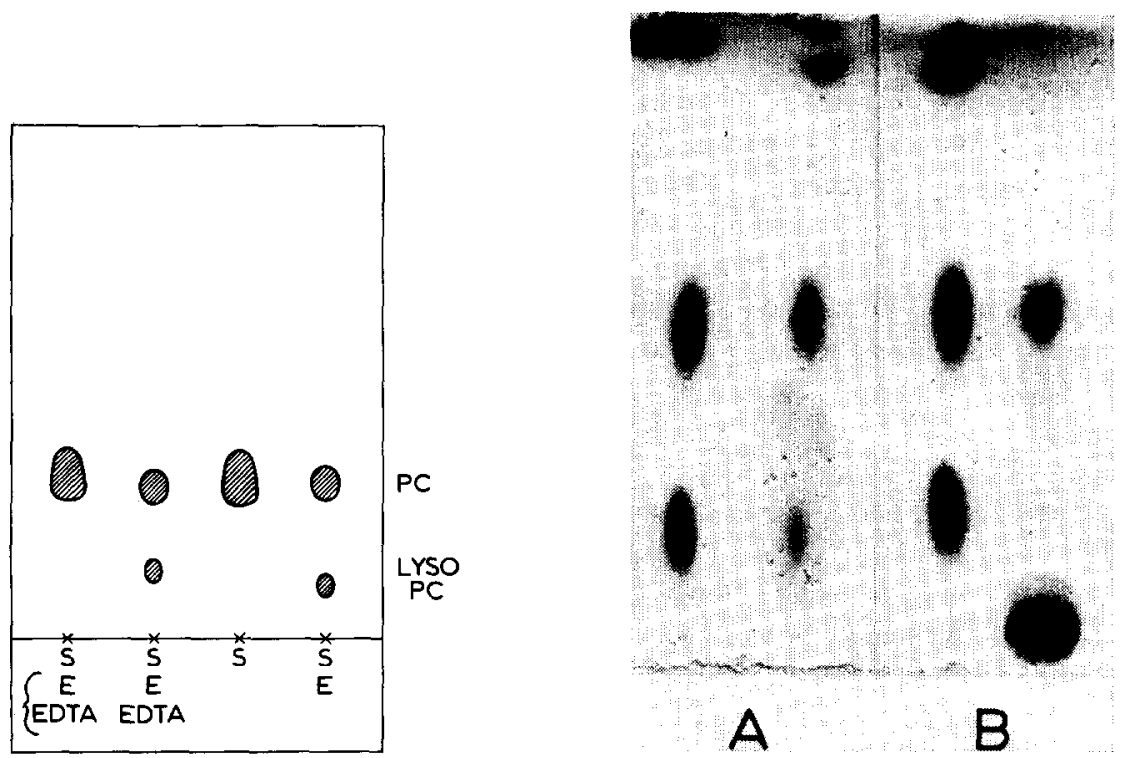

Fig. I. Silica impregnated paper chromatogram of phospholipase A hydrolysis. Aqueous suspensions of soya lecithin substrate (S) and Crotalus adamanteus venom (E) were separately applied to paper, substrate first. Column I: substrate, then venom and EDTA together; Column 2 : substrate then venom followed by EDTA; Column 3 : substrate alone; Column 4 : substrate followed by venom. Spots were identified by tricomplex staining.

Fig. 2. Ice-cold mixtures of soya lecithin and snake venom applied to thin-layer chromatography. Left hand lane of each thin-layer chromatogram contains standards, from above: linoleic acid, soya lecithin and egg lysolecithin. In A reaction mixture was applied directly to right-hand lane. In $\mathrm{B}$ excess cold EDTA solution was mixed with the same reaction mixture prior to thin-layer chromatographic application. 
paper (Fig. I). Here again the silica stimulated the reaction in the presence of $\mathrm{Ca}^{2+}$, but not when $\mathrm{Ca}^{2+}$ was removed by EDTA.

\section{Phospholipase A in bulk systems}

When phospholipase $\mathrm{A}$ and soya or egg lecithin were mixed at $0^{\circ}$ and applied to thin-layer chromatographic plates for room temperature chromatography, activation by the silica gel was similar to that found above with separate enzyme and substrate application. Again, all three enzymes were activated. Fig. $2 \mathrm{~A}$ shows the hydrolysis of an ice-cold suspension of soya lecithin by snake venom apparently occurring after application to the thin-layer chromatographic plate. In Fig. $2 \mathrm{~B}$ the same suspension was mixed with ice-cold EDTA solution prior to thin-layer chromatographic application. In this case no hydrolysis of lecithin took place. When the original EDTA-free mixture was incubated for $20 \mathrm{~min}$ at room temperature prior to EDTA addition, there was approximately 5-I0\% hydrolysis of the lecithin. The addition of an equal volume of $\mathrm{I} \mathrm{M} \mathrm{HCl}$ also inhibited further hydrolysis, even on the thin-layer chromatographic plate. Nevertheless, when reaction mixtures were subjected to FolCH et al. or BLIGH AND DYER extractions without EDTA or acid, somewhat more hydrolysis could be demonstrated than when EDTA was added, indicating that these extraction procedures do not completely abolish enzymic activity. Io $\%$ ether in reaction mixtures greatly accelerated hydrolysis both in the bulk and in samples applied to thin-layer chromatographic plates. Silica gel $\mathrm{H}$ (o.I g per $2 \mathrm{ml}$ ) added to bulk mixtures accelerated reactions to a greater extent than did $10 \%$ ether, as judged by $\mathrm{H}_{2} \mathrm{SO}_{4}$ charring. In an extreme case, approximately $95 \%$ hydrolysis of soya lecithin was achieved by adding $0.3 \mathrm{~g}$ Silica gel $\mathrm{H}$ to $2 \mathrm{ml}$ of solution containing $7.5 \mu$ moles lecithin and roo $\mu \mathrm{g}$ snake venom, incubating for Io min and then running on a thin-layer chromatographic plate.

Table I and Fig. 3 give the results of snake venom hydrolysis of soya lecithin.

\section{TABLE I}

PERCENT LECITHIN REMAINING AFTER PHOSPHOLIPASE A HYDROLYSIS

Unsonicated soya lecithin $(3.5 \mathrm{mM})$ was hydrolysed by Crotalus adamanteus venom $(63 \mu \mathrm{g} / \mathrm{ml})$. Results are from duplicate phosphorus analyses.

\begin{tabular}{|c|c|c|c|c|}
\hline \multirow[b]{2}{*}{ Time (min) } & & \multicolumn{3}{|c|}{$\%$ Lecithin remaining } \\
\hline & & 0 & 2 & 20 \\
\hline Control & & 96.8 & 95.6 & $9 I \cdot 4$ \\
\hline I0\% ether $(v / v)$ & & $97 \cdot 7$ & $54 \cdot 7$ & 9.3 \\
\hline Io\% silica gel $(w / v)$ & Io $\mathrm{mM} \mathrm{Ca}{ }^{2+}$ & $94 \cdot 3$ & 45.0 & I I.O \\
\hline & $100 \mathrm{mM} \mathrm{Ca}{ }^{2+}$ & 94.3 & $3^{8} \cdot 3$ & 5.1 \\
\hline
\end{tabular}

The data were obtained by quantitative phosphorus analysis of thin-layer chromatographic spots. One can see that hydrolysis is accelerated in the presence of $10 \%$ ether and that Silica gel $\mathrm{H}$, o.I $\mathrm{g} / \mathrm{ml}$, results in an even greater rate of breakdown. Reactions werc stopped with EDT $\Lambda$ and a BLIGH AND Dyen cxtraction.

In another series of experiments, $\mathrm{H}_{2} \mathrm{SO}_{4}$ charring of thin-layer chromatographic plates was used to gauge hydrolysis following bulk incubation with silica and with ether. Reaction samples subjected to EDTA FOLCH et al. extraction showed less hydrolysis than those applied directly to thin-layer chromatographic plates, indicat- 


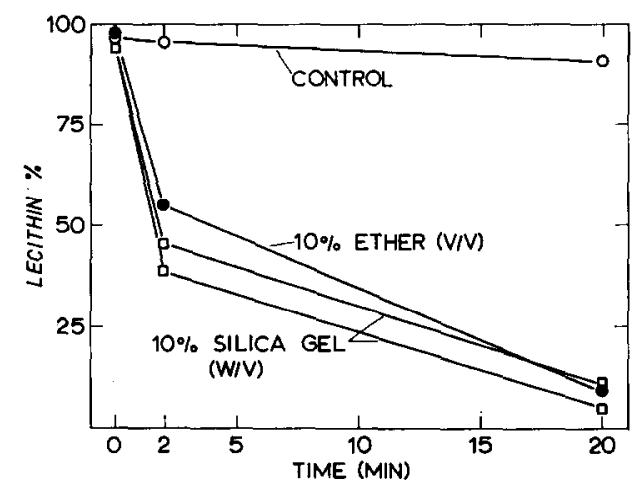

Fig. 3. Soya lecithin hydrolysis by phospholipase A. Substrate was soya lecithin; enzyme was Crotalus adamenteus venom. Phosphorus analysis of duplicate iodine identified spots. Upper silica gel curve: Io $\mathrm{mM} \mathrm{Ca}{ }^{2+}$, lower: 100 $\mathrm{mM} \mathrm{Ca}^{2+}$.

ing that an important fraction of the breakdown could occur on the thin-layer chromatographic plate even after stimulation in the bulk.

\section{pH-stat measurements}

In order to measure phospholipase A activity in a non-chromatographic system, we utilized a $\mathrm{pH}$-stat in the manner of DE HaAs et al. ${ }^{12}$. Fig. 4 shows the results of several such experiments. These studies indicate that non-sonicated soya lecithin suspensions are hydrolyzed quite slowly, although at rates somewhat greater than egg lecithin. When the stock suspensions were sonicated to clarity, however, the rates of splitting increased. $\mathrm{H}_{2} \mathrm{SO}_{4}$ charred thin-layer chromatographic plates of $\mathrm{HCl}$ and EDTA-treated samples visually confirmed the $\mathrm{pH}$-stat measurement of $20 \%$ hydrolysis. When EDTA was added to the reaction mixture at this point, there was a step change in the titration record due entirely to $\mathrm{Ca}^{2+}-\mathrm{H}^{+}$exchange on the EDTA.

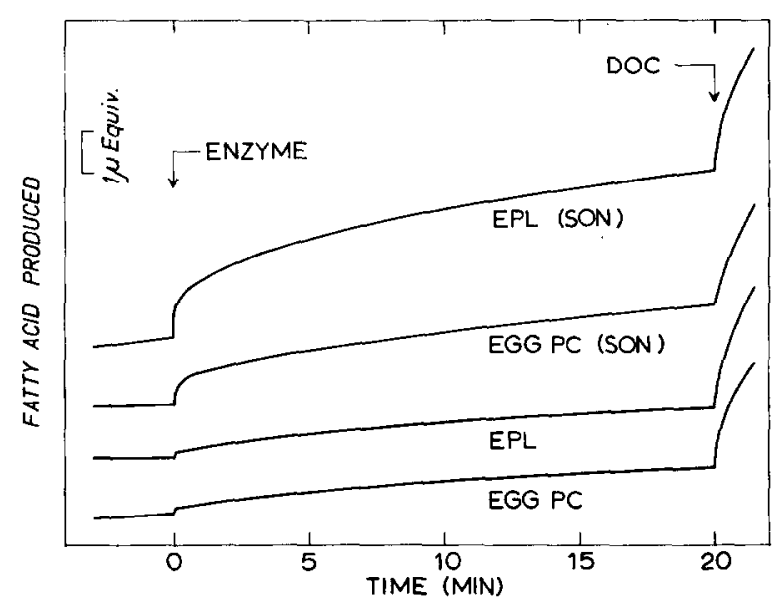

Fig. 4. pII-stat tracings of Crotalus adamanteus venom action on sonicated (SON) and unsonicated egg(EGG PC) and soya (EPL) lecithins. Deoxycholate (DOC) was added and reaction followed to completion to determine titration efficiency. 
Following this the $\mathrm{pH}$ remained constant, indicating that no further deacylation was occurring. $20 \mathrm{mg}$ of silica gel added to the original incubation mixture increased the rate of hydrolysis, and Ioo $\mathrm{mg}$ produced an even greater increase in rate, although the rather large buffering capacity of silicic acid considerably reduced the sensitivity of the $\mathrm{pH}$-stat system. It was also seen that whereas ether ( $\mathrm{I} \mathrm{ml}$ per $4 \mathrm{ml}$ aqueous media) greatly accelerated hydrolysis, methanol ( $2 \mathrm{ml}$ per $4 \mathrm{ml}$ aqueous media) slowed but did not stop the reaction.

\section{Phospholipase $C$ activity}

Because of the remarkable silica activation of phospholipase A, phospholipase $C$ was subjected to the same tests. While there was an indication that small amounts of soya lecithin were hydrolyzed by phospholipase $C$ after application to silica gel plates, the activity was in no way comparable to phospholipase A. EDTA was found, however, to abolish this activity, confirming the necessary role of $\mathrm{Ca}^{2+}$ in the hydrolysis.

\section{Lipase activity}

The action of lipase on triolein was studied in a similar set of experiments. Aqueous silica gel suspensions of triolein, $7.5 \mathrm{mM}$, showed no demonstrable hydrolysis after 90-min incubations with lipase, $50 \mu \mathrm{g} / \mathrm{ml}$. In great contrast, the same concentration of sonicated triolein was $95 \%$ hydrolyzed within $20 \mathrm{~min}$ in the presence of $5 \mu \mathrm{g} / \mathrm{ml}$ lipase. The addition of silica gel to this latter system did not alter the breakdown rate significantly. Adding $\mathrm{Ca}^{2+}$ or EDTA to the reaction mixtures had no effect on hydrolysis.

\section{DISCUSSION}

The effects of silicic acid on phospholipase A activity described above are so gross that they can easily be visualized by $\mathrm{H}_{2} \mathrm{SO}_{4}$ charring of small thin-layer chromatographic plates. It seemed pointless to pursue extensive quantitative phosphorus analyses of this reaction inasmuch as the specific surface area of silica gel preparations varies, and the application and drying of aqueous mixtures on thin-layer chromatographic plates is such a poorly characterized process. Table I, however, has been included to indicate more quantitatively the magnitude of silica gel stimulation under a particular set of circumstances, and to compare it with a known activator, ether. The $\mathrm{pH}$-stat assay method, a non-chromatographic process, was used to confirm the thin-layer chromatographic findings. Our assumption that this method gives a linear representation of hydrolysis for aqueous dispersions may not be wholly valid in view of the fact that ion concentrations near fatty acid-rich surfaces will differ from bulk ion concentrations ${ }^{13}$.

Aqueous unsonicated soya lecithin was hydrolyzed only slowly by phospholipase $\mathrm{A}$ in the absence of activating agents. When silicic acid was added, however, cither to the $\mathrm{pH}$-stat or to the bulk system, there was a remarkablc stimulation of activity. Furthermore, activation was also observed particularly well on silicic acid thin-layer chromatographic plates or impregnated paper. The evidence for this latter activation derives both from the application of ice-cold mixtures of enzyme and substrate to thin-layer chromatographic plates and from the separate application of en- 
zyme and substrate to the same thin-layer chromatographic origin spot. Phospholipase A stimulation by silica gel in a bulk mixture exceeded that of ether when quantitative phosphorus determinations of lysolecithin and lecithin were done. Since all three phospholipase A preparations were activated by silica gel, the process seems to be one of rather general applicability and interest. It seems likely that silica gel stimulates in a similar manner to deoxycholate by providing a more favorable dispersion of lipid substrate than is obtained in non-sonicated aqueous suspensions. When such simple lecithin dispersions are sonicated, the increased surface area of the resulting preparations allows a more rapid hydrolysis by phospholipase A. Sonication seems to accelerate lipase action on triolein in the same manner. Although silica gel dispersed substrate effectively, it seemed to have little effect on phospholipase $\mathrm{C}$ or lipase.

Concerning the influence of solvents on the action of phospholipase $\mathrm{A}$, our $\mathrm{pH}$ stat data have shown that methanol can slow the rate of lecithin hydrolysis. This is still consistent with the findings of others who have suggested that phospholipase A activity might persist during organic extraction procedures ${ }^{1,2}$. Our methods, however, were not suited to a quantitative evaluation of this question. Nevertheless, since methyl isobutyl ketone is known to activate phospholipase $\mathrm{A}^{2,4}$, the use of this and similar compounds as developing solvents may well create difficulties unless the media are kept sufficiently acidic.

In view of the above findings it would seem wise to stop phospholipase A activity with acid or EDTA so that hydrolysis does not occur later during chromatography.

The results of these investigations may shed some light on an interesting reaction proposed by FRANCK, HÖLZL AND WAGNER ${ }^{5}, 14,15$ in which the addition of EDTA to a mixture of lecithin and phospholipase A was said to produce lecithin by reacylation of the lysolecithin already formed. This conclusion followed from their finding that incubation mixtures to which EDTA had been added contained little or no lysolecithin on analysis, whereas the control samples without EDTA showed $40-70 \%$ hydrolysis of the original lecithin within a $2-5$-min reaction period. These authors effected separation of products by applying aliquots of reaction media directly to silica gel impregnated paper or formaldehyde treated paper, and in other cases added silica to their samples prior to freeze drying. It is therefore likely that their data demonstrate not a reacylation due to EDTA, but a stimulation of phospholipase A activity in their controls due to silica gel. This occult stimulation also becomes manifest in their controls, which exhibit very rapid reaction ratcs. Thesc high control reaction rates in turn result in an apparently low stimulation of ether (Crotalus terr. terr.; nil at $2 \mathrm{~min}$ and $\mathrm{I} .5$-fold increase in hydrolysis at $30 \mathrm{~min}$; Crotalus adamanteus: I.I- and I.6-fold increases, respectively) and deoxycholate (pancreatin: I.2-fold increase at $2 \mathrm{~min}$ and $\mathrm{I} .7$-fold increase at $20 \mathrm{~min}$ ). These results are to be contrasted with the greater ether stimulation noted by DAwson ${ }^{4}$ (Naja naja: 3.5fold increase in hydrolysis) and the greater deoxycholate stimulation reported by IBRAHIм $e t$ al. ${ }^{6}$ (pancreatic: 28 -fold increase in hydrolysis). These latter authors stopped their reactions with isopropanol-heptane $-\mathrm{H}_{3} \mathrm{SO}_{4}{ }^{4}$ and ethanol-hydroxylamine ${ }^{6}$.

Finally, the rather strong silica gel stimulation of phospholipase A suggests that it might easily be incorporated into analytical or preparative schemes. In such cases, a reaction could be taken to completion on a damp thin-layer chromatographic

Biochim. Biophys. Acta, $24^{8}$ (1971) 245-253 
origin with simple chromatographic separation of the reaction products on the same plate. Similarly silica gel could be used to stimulate bulk phospholipase A reaction mixtures when the use of ether or deoxycholate was inconvenient.

NOTE ADDED IN FROOF

(Received October IIth, I97I). Munder, Modolell, and Fischer (Biochem. Z., 344 (I966) 3I0) have described a marked increase in phospholipase A activity of macrophages exposed to finely divided quartz.

\section{ACKNOWLEDGMENTS}

This work was done during J. Goerke's tenure as an American Heart Association Established Investigator.

\section{REFERENCES}

i L. L. M. Van Deenen, G. H. De HaAs, and C. H. Th. Heemskerk, Biochim. Biophys. Acta, $67(1963) 295$.

2 W. L. MageE and R. H. S. Thompson, Biochem. J., 77 (1960) 526.

3 D. J. Hanahan, J. Biol. Chem., I95 (I952) 199.

4 R. M. C. Dawson, Biochem., J. 88 (1963) 4 I 4.

5 H. P. Franck, J. Hölzz and H. WaGner, $Z$. Naturforsch., 23b (1968) 439.

6 S. A. Ibrahim, H. Sanders and R. H. S. Thompson, Biochem. J., 93 (1964) 588.

7 D. J. Hanahan, J. C. Dittmer and E. Warashina, J. Biol. Chem., 228 (i957) 685.

8 J. Folch, M. Lees and G. H. Sloane-Stanley, J. Biol. Chem., 226 (I957) 497

9 E. G. Bligh and W. J. Dyer, Can. J. Biochem. Physiol., 37 (r959) 9 т r.

io C. H. Fiske and Y. Subbarow, J. Biol. Chem., 66 (I925) 375.,

it H. G. Bungenderg de Jong, Proc. Koninkl. Ned. Akad. Wetensch. Ser. B., Phys. Sci., 64 (1961) 467.

i2 G. H. De IIaAs, P. P. M. Bonsen, W. A. Pieterson and L. L. M. Van Deenen, Biochim. Biophys. Acta, 239 (1971) 252.

I3 J. Goerke, M. Borowitz and H. Harper, The Interaction of Calcium with Monolayers of Steric and Oleic Acids, in M. Blank, Surface Chemistry of Biological Systems, Plenum Press, New York, 1970.

I4 J. HölzL AND H. WagNer, $Z$. Naturforsch., 23 b (1968) 449.

I 5 H. P. Franck, J. Hölzl and H. WaGner, Z. Naturforsch., 25b (1970) 58 I.

Biochim. Biophys. Acta, $24^{8}$ (197I) 245 -253 